\title{
INTER-OBSERVER VARIATION IN CLINICAL OPTIC DISC BIOMETRY
}

\author{
A. A. E. PYOTT ${ }^{1}$ and D. M. I. MONTGOMERY ${ }^{2}$ \\ Glasgow
}

\begin{abstract}
SUMMARY
This study investigated the inter-observer reproducibility of measurements of the optic nerve head as carried out with a clinical optic disc biometer. This instrument employs a modification of indirect ophthalmoscopy to enable measurement of fundus structures. Measurements were made independently by two observers on 84 eyes of 47 patients. The median inter-observer differences for each measurement were as follows: maximum disc diameter, $0.085 \mathrm{~mm}$; minimum disc diameter, $0.080 \mathrm{~mm}$; maximum cup diameter, $0.098 \mathrm{~mm}$; minimum cup diameter, $0.078 \mathrm{~mm}$; disc area, $0.225 \mathrm{~mm}^{2}$; neuroretinal rim area, $0.215 \mathrm{~mm}^{2}$. Utilising the above measurements, the instrument automatically calculates a 'rim index' to take account of variations in disc size. It then interprets the disc as normal, suspicious or glaucomatous. The optic disc biometer produced seriously conflicting interpretations in 8 discs, 7 of which had been judged by both observers to have indistinct boundaries of the disc or cup.
\end{abstract}

Before any novel analytical technique can be embraced as useful it is important to establish its measurement reproducibility. Where operator subjectivity is a significant factor it is particularly important to evaluate both intra-observer and inter-observer variability. Recently one of us (D.M.) has described a new method of making measurements of structures at the posterior pole of the fundus. ${ }^{1}$ In examination of the optic nerve head, intraobserver variability of measurement has been shown to be acceptable and the method shows promise for the detection of glaucomatous damage. ${ }^{2,3}$ This technique of optic disc biometry is essentially a modification of indirect ophthalmoscopy whereby an optical spacer allows a fixation target to be introduced at the principal plane of a 15 dioptre condensing lens. With steady fixation maintained,

From: ${ }^{1}$ Department of Ophthalmology, Southern General Hospital, Glasgow; ${ }^{2}$ Tennent Institute of Ophthalmology, Western Infirmary, Glasgow, UK

Correspondence to: Dr Donald Montgomery, Senior Registrar, Tennent Institute of Ophthalmology, Western Infirmary, Glasgow G11 6NT, UK. it is possible to make measurements of the ariel image formed at this plane. The technique has now been refined in the development of the optic disc biometer. This instrument employs electronic digital calipers which enter the disc image measurements directly into a microprocessor unit that then automatically calculates the real disc and cup dimensions (see Fig. 1). From these data it calculates values for the disc, cup and neuroretinal rim areas. By comparing the measured rim area with the rim area expected in a disc of a given size the biometer interprets the disc as normal, suspicious or glaucomatous.

To date the technique has been used only by its innovator. The purposes of this study were to assess how easily it could be mastered by a 'novice' and to determine the level of agreement that could be obtained between the two observers.

\section{MATERIALS AND METHODS}

Eighty-four eyes of 47 patients were independently examined by two observers (D.M. and A.P.) using the optic disc biometer. Patients were recruited from general outpatient clinics and a wide range of ocular diagnoses were embraced. Amongst these were 20 eyes in which a diagnosis of primary open angle glaucoma had been established and a further 8 eyes with ocular hypertension. The

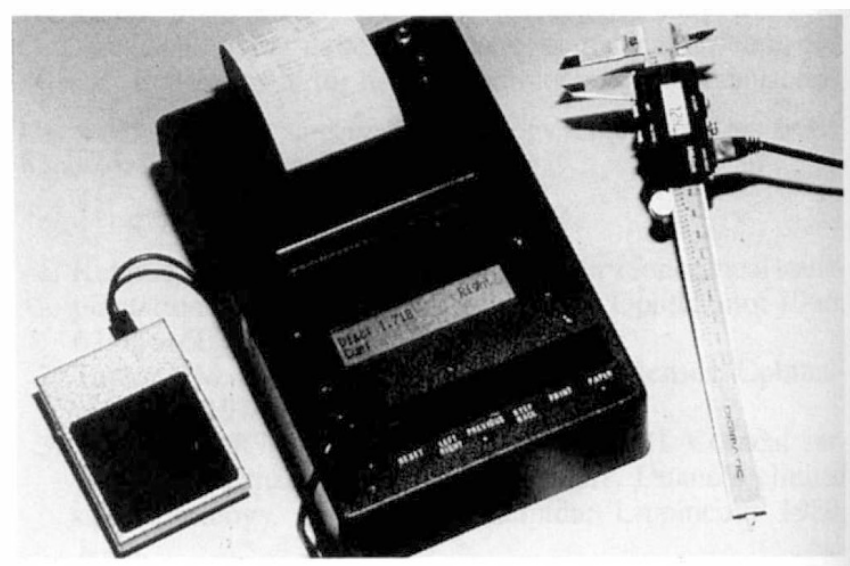

Fig. 1. The optic disc biometer. 
mean refractive error was $+0.65 \pm 2.45$ dioptres (range -8.00 to +6.00 dioptres). Eyes were excluded if mydriasis was insufficient to allow a stereoscopic view of the posterior pole, if they had significant media opacity or if they were unable to maintain fixation. All patients were given a full explanation of the examination to be carried out and their consent was obtained. No discussion of diagnosis was entered into prior to the examination, but following the procedure each observer made an independent evaluation of the subjective difficulty of the test. This depended primarily on the definition of the boundaries of both the disc and cup and was graded from 1+ (very easy) to 4+ (very difficult).

Each observer made four measurements on each eye, namely the maximum and minimum diameters of both the disc and its cup. Each set of measurements took about 1 minute to complete per eye. By pressing a footswitch, these measurements were entered directly to the microprocessor unit which then calculated the disc, cup and neuroretinal rim areas according to the formulae given elsewhere. ${ }^{2}$

A further derived value was also calculated, namely the 'rim index'. This is a recently described concept which allows the rim area to be expressed in a form which takes account of the disc size. ${ }^{3}$ Several studies have shown that there is considerable variation in disc size and neuroretinal rim area among normal eyes but that there is a good correlation between the size of the disc and the area of the neuroretinal rim. ${ }^{4-6}$ It is therefore possible to predict the rim area expected in a healthy disc of a given size. The ratio of the measured rim area to this expected area defines a 'rim index' which may be a useful indicator of neural tissue loss.

\section{RESULTS}

Regarding the subjective impressions of the difficulty of individual examinations, there was close agreement between the two observers with no disagreement greater than one place on the linear scale. Where there was disagreement, the higher value is quoted. The number of eyes in each category is shown in Table I. It can be seen that a minority of examinations (32/84) were considered to fall into the easier categories of 1 or 2 .

The degree of inter-observer difference for the various parameters is shown in Fig. 2. For each histogram the median value for each parameter is given, as is the median inter-observer difference of the measurements. The median percentage difference is calculated by dividing the latter by the former and multiplying the result by 100 . Fig.

Table I. Grading of discs according to subjective difficulty

\begin{tabular}{cc}
\hline Disc grading & Number \\
\hline 1 & 7 \\
2 & 25 \\
3 & 33 \\
4 & 19 \\
& $\frac{19}{84}$ \\
\hline
\end{tabular}

$2 \mathrm{a}$ and $2 \mathrm{~b}$ show the values for the measurements of the maximum and minimum diameters of the optic disc. The median differences in each case were $0.085 \mathrm{~mm}$ and $0.080 \mathrm{~mm}$ respectively. These correspond to percentage differences of $4.45 \%$ and $4.79 \%$. Fig. $2 \mathrm{c}$ and $2 \mathrm{~d}$ show the values for the maximum and minimum cup diameters. Here the differences were $0.098 \mathrm{~mm}$ and $0.078 \mathrm{~mm}$. As the absolute cup diameters were relatively small, the corresponding percentage differences rise to $13.2 \%$ and $11.0 \%$.

From the four measurements above, the microprocessor unit calculated the disc and neuroretinal rim areas. Fig. 2e and $2 \mathrm{f}$ show that the median inter-observer differences for these parameters were $0.225 \mathrm{~mm}^{2}$ and $0.215 \mathrm{~mm}^{2}$, corresponding to percentage differences of $8.63 \%$ and $10.9 \%$ respectively.

Given the importance of the derived 'rim index' value we have afforded this particular scrutiny. Fig. 3a shows the overall inter-observer difference in 'rim index'. The median percentage difference was $8.23 \%$.

The optics of the indirect ophthalmoscope dictate that the position of the condensing lens relative to the patient's eye may affect the magnification of the image. ${ }^{7}$ This becomes particularly significant when the refractive error of the eye is greater than 3 dioptres from emmetropia. ${ }^{2}$ Fig. $3 \mathrm{~b}$ illustrates separately the inter-observer differences in calculated 'rim index' in eyes with errors less than and greater than 3 dioptres. The results of the two groups were not found to differ significantly (two-sample $t$-test; $P=0.16$ ). Fig. $3 \mathrm{c}$ and $3 \mathrm{~d}$ subdivide the eyes according to subjective difficulty of examination. As might be expected, inter-observer differences were lower in categories 1 and 2 compared with categories 3 and 4 (twosample $t$-test; $P=0.0045$ ).

The most critical inter-observer variation relates to the diagnostic classification of the optic discs. Fig. 4 is a matrix illustrating the diagnostic agreement between the two observers. Perfect agreement was found in over $70 \%$ of cases. It is perhaps more meaningful, however, to consider the cases in which there was serious diagnostic disagreement, i.e. where observer 1 calculated a disc to be normal while observer 2 calculated it to be abnormal. This occurred in only 8 eyes (9.5\%), 7 of which were in the difficult categories of 3 or 4 .

\section{DISCUSSION}

Accurate assessment of the integrity of the optic nerve head is an essential part of the evaluation of any patient suspected of having glaucoma, yet it is a task fraught with difficulty. In 1967 Armaly $^{8}$ popularised the concept of the cup/disc ratio and this is still widely used. Many workers have, however, expressed unease with the degree of confidence placed in such estimations. Kahn et al. ${ }^{9}$ confirmed suspicions that there is a high degree of inter-observer variability in the estimation of the cup/disc ratio and surprisingly found that training sessions designed to standardise parameters actually worsened this trend. They also reported wide diagnostic disagreement between experts 
maximum disc diameter

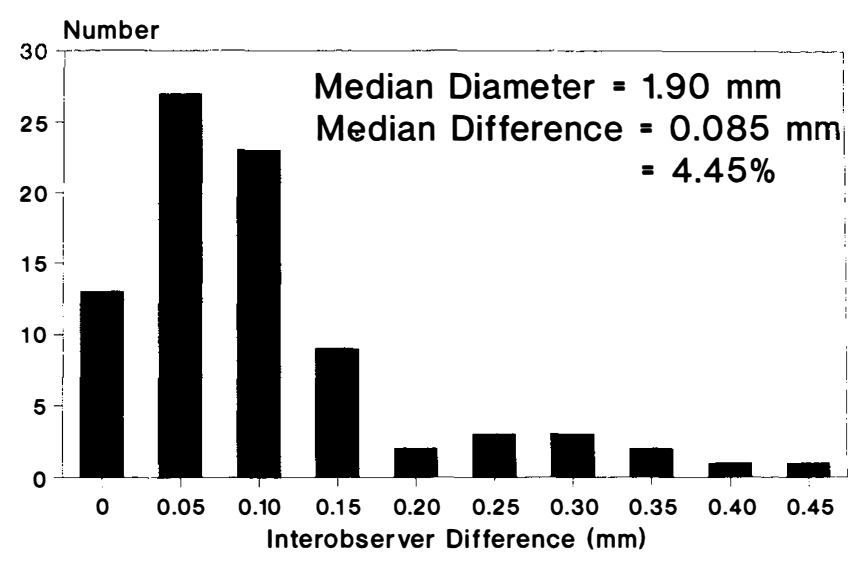

(a)

maximum cup diameter

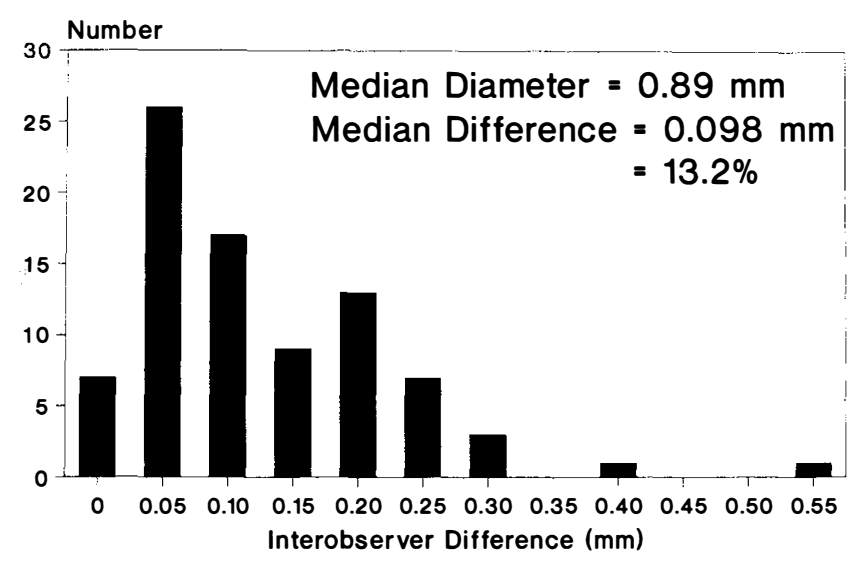

(c)

\section{Disc area}

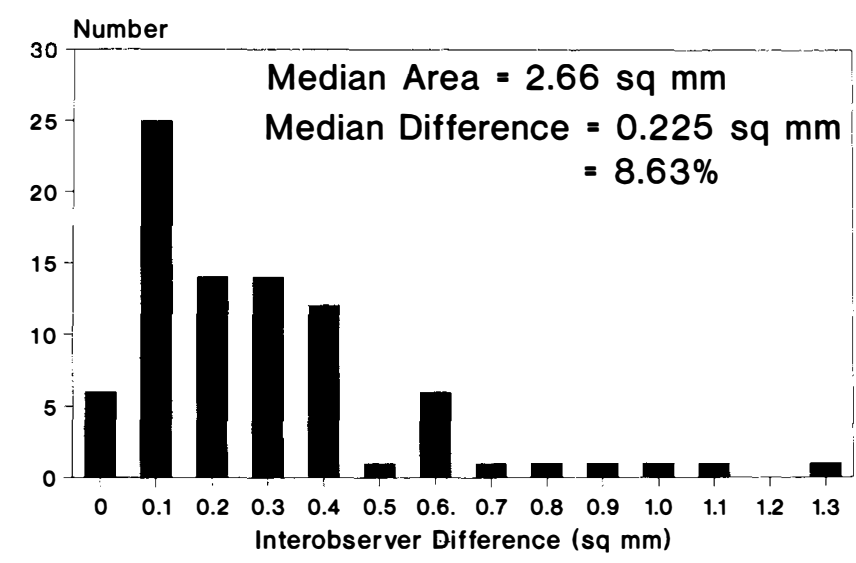

(e) minimum disc diameter

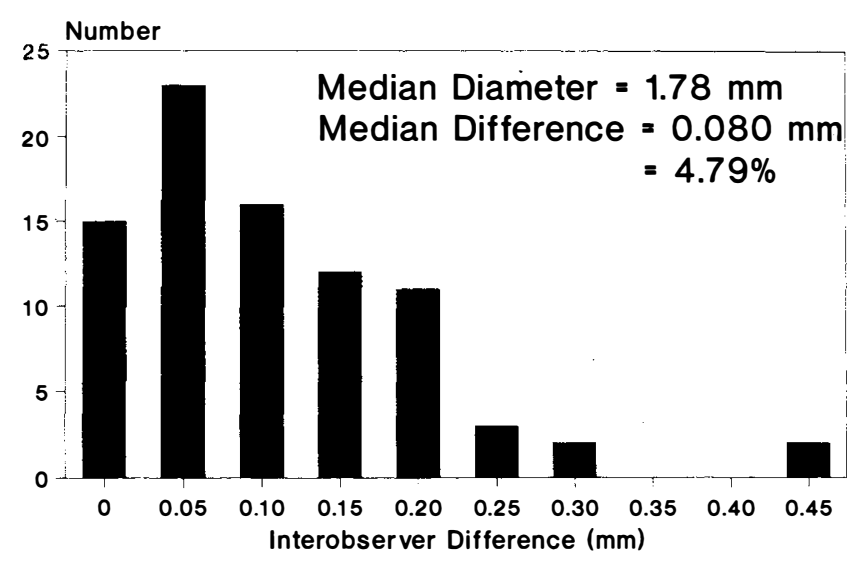

(b)

minimum cup diameter

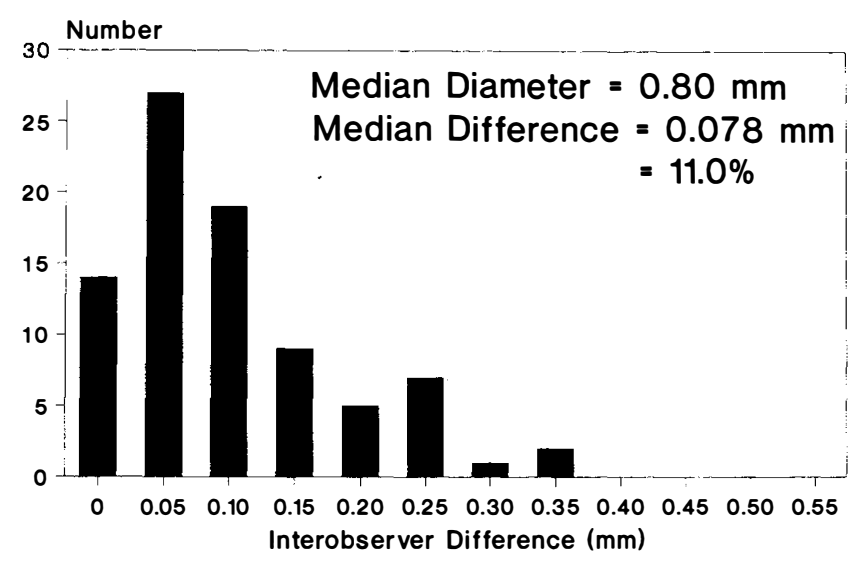

(d)

neuroretinal rim area

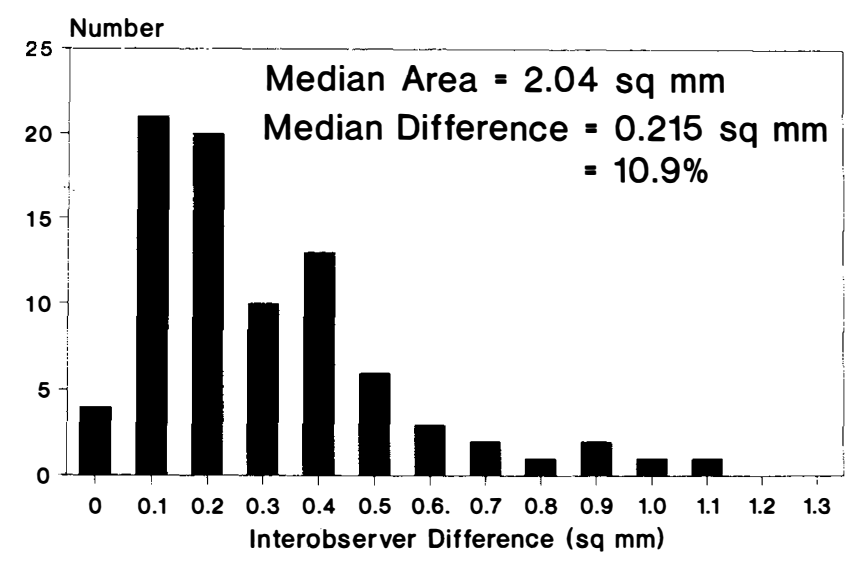

(f)

Fig. 2. Inter-observer differences for measurement of disc and cup diameters, and disc and neuroretinal rim areas.

and, paradoxically, even when there was tighter agreement on higher values of cup/disc ratio, this was not reflected in agreement that a disc was glaucomatous. Clearly there is a highly subjective element to this method of assessment, which has led Lichter ${ }^{10}$ to conclude that 'Cup/disc ratios are an inexact method of recording the status of a disc.'

It has been suggested that loss of over $20 \%$ of axons is required to produce a $5 \mathrm{~dB}$ decrease in threshold across the visual field. ${ }^{11}$ This decrease is reflected in a reduction in the area of the neuroretinal rim. Attention has therefore focussed on the measurement of this parameter as a possible discriminator between normal and glaucomatous discs. ${ }^{12-15}$ Other workers have, however, questioned its value in view of its wide normal range and the overlap 
rim index

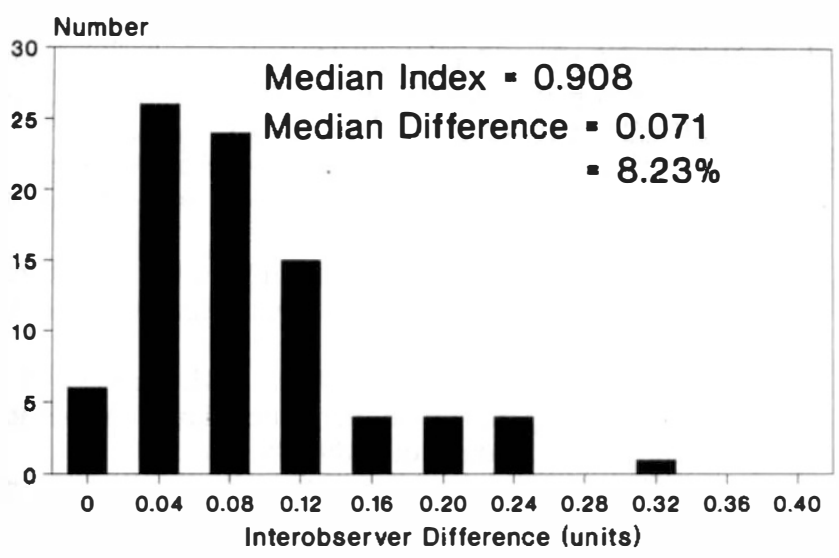

(a)

\section{rim index}

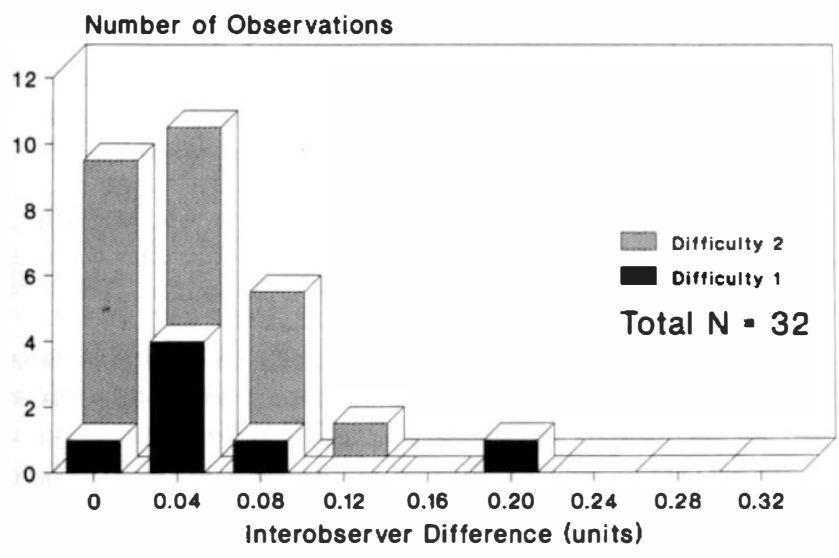

(c) rim index

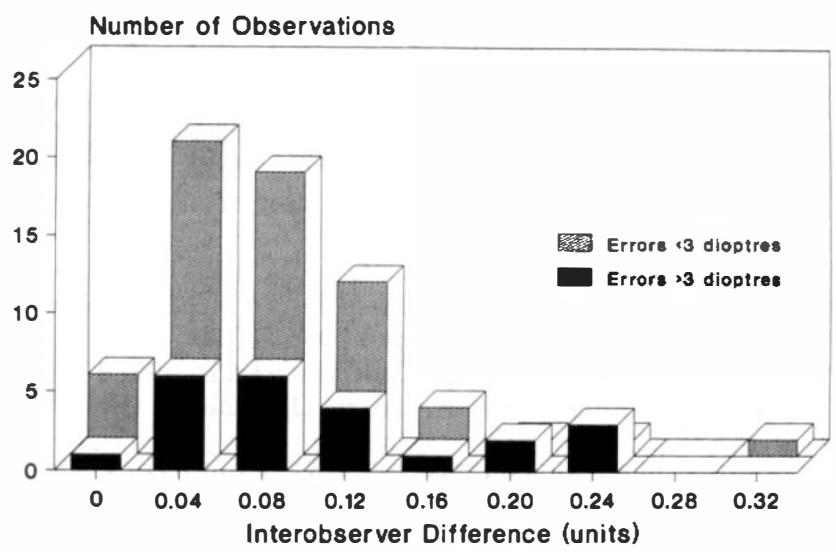

(b)

rim index

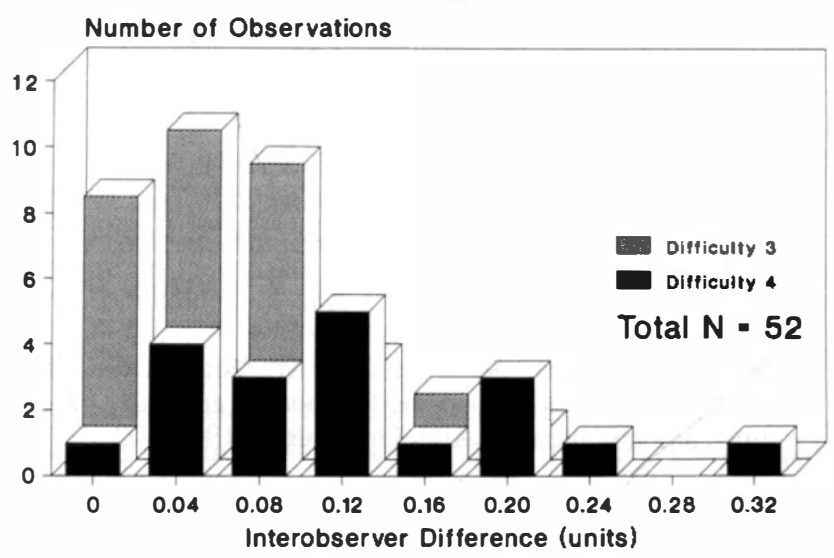

(d)

Fig.3. Inter-observer differences for calculation of rim index: (a) overall results, $(b)$ according to refractive index, $(c, d)$ according to subjective difficulty.

with the glaucomatous population. ${ }^{16-18}$ This wide range is a consequence of the even greater normal range of disc area. ${ }^{19}$ Since the calculation of the 'rim index' takes account of the correlation of rim area with disc area and effectively compares the rim area with that of an 'idealised standard' of similar disc size, this parameter might be expected to have greater discriminating value.

\section{Observer 1}

$\begin{array}{rccc} & N & G & S \\ N & 41 & 1 & 3 \\ \text { Observer 2 G } & 7 & 18 & 8 \\ S & 3 & 2 & 1\end{array}$

Fig. 4. A matrix illustrating diagnostic variation between the two observers. $N$, normal; $G$, glaucomatous; $S$, suspicious. Cases of serious diagnostic disagreement are highlighted.
Table II. Inter-observer variation compared with literature reports of automated disc analysis

\begin{tabular}{|c|c|c|}
\hline \multirow[b]{2}{*}{ Reference } & \multicolumn{2}{|c|}{ Interobserver variation } \\
\hline & Disc area $(\%)$ & Neuroretinal rim area $(\%)$ \\
\hline Present study & 8.63 & 10.9 \\
\hline${ }^{\mathrm{a}}$ Caprioli et al ${ }^{20}$ & 6.2 & 7.7 \\
\hline${ }^{\mathrm{a} S h i e l d s}$ et $a l^{21}$ & -2 & 6.1 \\
\hline${ }^{b}$ Varma et al. ${ }^{22}$ & - & $5-21^{c}$ \\
\hline
\end{tabular}

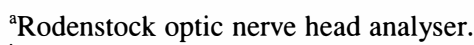

${ }^{\mathrm{b}}$ Topcon IS 2000 system.

${ }^{\mathrm{c}}$ Variability differed depending on individual disc configurations.

In an attempt to improve objectivity of assessment, automated techniques of optic disc analysis have been advocated. $^{20-22}$ The degree of inter-observer variability in clinical disc biometry compares quite favourably with equivalent observations with these highly sophisticated methods (Table II). Refractive error appeared to have relatively little influence on the inter-observer variation while the lack of definition of the disc and cup boundaries was a limiting factor in some cases.

Key words: Glaucoma, Measurement, Optic disc, Variability. 


\section{REFERENCES}

1. Montgomery DMI. The optical spacer: a simple device which extends the scope of indirect ophthalmoscopy. Br J Ophthalmol 1992;76:45-6.

2. Montgomery DMI. Measurement of optic disc and neuroretinal rim areas in normal and glaucomatous eyes: a new clinical method. Ophthalmology 1991;98:50-9.

3. Montgomery DMI. Clinical disc biometry in early glaucoma. Ophthalmology 1993;100:52-6.

4. Britton RJ, Drance SM, Schulzer M, Douglas GR, Mawson DK. The area of the neuroretinal rim of the optic nerve in normal eyes. Am J Ophthalmol 1986;103:497-504.

5. Caprioli J, Miller JM. Optic disc rim area is related to disc size in normal subjects. Arch Ophthalmol 1987;105: 1683-5.

6. Bottoni FG, Gonnella PM, Porta AS, Consalez GG. Neuroretinal rim area in normal eyes: a study on a randomised group of 30 subjects. Ophthalmologica 1989;198:40-5.

7. Elkington AR, Frank HJ. Clinical optics. Oxford: Blackwell Scientific, 1984:132-4.

8. Armaly MF, Sayegh RE. The cup/disc ratio: the findings of tonometry and tonography in the normal eye. Arch Ophthalmol 1969;82:191-6.

9. Kahn HA, Leibowitz H, Ganley JP, Kini M, et al. Standardising diagnostic procedures. Am J Ophthalmol 1975;79:768-75.

10. Lichter PR. Variability of expert observers in evaluating the optic disc. Trans Am Ophthalmol Soc 1976;74:532-72.

11. Quigley HA, Dunkelberger GR, Green WR. Retinal ganglion cell atrophy correlated with automated perimetry in human eyes with glaucoma. Am J Ophthalmol 1989; 107:453-64.

12. Balazsi G, Drance SM, Schulzer M, Douglas GR. Neuroretinal rim area in suspected glaucoma and early chronic open angle glaucoma. Arch Ophthalmol 1984;102:1011-4.
13. Airaksinen PJ, Drance SM, Douglas GR, Schulzer M. Neuroretinal rim areas and visual field indices in glaucoma. Am J Ophthalmol 1985;99:107-10.

14. Funk J, Bornscheuer C, Grehn F. Neuroretinal rim area and visual field in glaucoma. Graefes Arch Clin Exp Ophthalmol 1988;226:431-4.

15. Funk J. Detection of progressive glaucomatous papilla changes before onset of visual field defects. Klin Monatsbl Augenheilkd 1991;198:271-6.

16. Caprioli J, Miller JM. Measurement of relative nerve fibre layer surface height in glaucoma. Ophthalmology 1989; 96:633-9.

17. Caprioli J, Ortiz-Colberg R, Miller JM, Tressler C. Measurements of peripapillary nerve fibre layer contour in glaucoma. Am J Ophthalmol 1989;108:404-13.

18. Quigley HA, Katz J, Derick RJ, Gilbert D, Sommer A. An evaluation of optic disc and nerve fiber layer examinations in monitoring progression of early glaucoma damage. Ophthalmology 1992;99:19-28.

19. Jonas JB, Gusek GC, Guggenmoos-Holzmann I, Naumann $\mathrm{GOH}$. Variability of the real dimensions of normal human optic discs. Graefes Arch Clin Exp Ophthalmol 1988; 226:332-6.

20. Caprioli MD, Klingbeil U, Sears M, Pope B. Reproducibility of optic disc measurements with computerised analysis of stereoscopic video images. Arch Ophthalmol 1986; 104:1035-9.

21. Shields MB, Martone JF, Shelton AR, Ollie AR, MacMillan J. Reproducibility of topographic measurements with the optic nerve head analyser. Am J Ophthalmol 1987;104: 581-6.

22. Varma R, Steinmann WC, Spaeth GL, Wilson RP. Variability in digital analysis of optic disc topography. Graefes Arch Clin Exp Ophthalmol 1988;226:435-42. 